\title{
Restless legs syndrome/Willis-Ekbom disease: new diagnostic criteria according to different nosology
}

\author{
S. MARELLI',2, A. GALBIATI',2, F. RINALDI ${ }^{3}$, E. GIORA ${ }^{1,2}$, A. OLDANI' \\ L. FERINI STRAMBI ${ }^{1,2}$, M. ZUCCONI \\ ' San Raffaele Scientific Institute, Dept of Clinical Neurosciences, Neurology, Sleep Disorders \\ Center, Milano, Italy; ${ }^{2}$ Vita-Salute San Raffaele University, Faculty of Psychology, Milano, Italy; ${ }^{3}$ \\ Clinica Neurologica, Spedali Civili di Brescia, Brescia University, Brescia, Italy
}

\begin{abstract}
A B S T R A C T
Restless Legs Syndrome/Willis Ekbom Disease (RLS/WED) is a common neurological disorder characterized by uncomfortable and unpleasant sensations in the legs, with an urge to move. The symptoms typically begin or worsen during periods of rest, in particular during the evening and at night, while the activity may typically relieve them. The majority of patients complains of poor sleep. Recent studies reported the prevalence ranging from 5 to 10\%. RLS/WED can be divided into primary (patients without associated conditions that may explain the symptoms) and secondary forms (mostly iron deficiency). RLS/WED is typically a chronic condition. The clinical course varies according to the age of onset. A great load of accumulating research and clinical data have led to an extended consensus for a need to enhance the diagnostic criteria. The aim of this paper is to provide a critical comparison among different diagnostic criteria, taking into account respectively the International Classification of Sleep Disorders (ICSD), the International RLS Study Group (IRLSSG) and the Diagnostic and Statistical Manual of Mental Disorders (DSM). There are several remarkable distinctions between the IRLSSG revised criteria, ICSD-3 and DSM-V. Contrary to the DSM-V criteria, ICSD-3 diagnostic criteria are more aligned to the IRLSSG ones. In fact, the five essential criteria of the IRLSSG are also required for the diagnosis of RLS/WED according to ICSD-3. The new IRLSSG criteria provide a more rigorous approach to case ascertainment and a better characterization of patients by specifying clinical significance and course. Future ascertainment of correct diagnosis should include documentation that all five diagnostic criteria are considered.
\end{abstract}

\section{Key Words \\ RLS/WED • Nosology $\bullet$ Sleep disorders $\bullet$ Diagnostic criteria $\bullet$ Movement disorder}

\section{Introduction}

In the $17^{\text {th }}$ century the English physician Thomas Willis mentioned a clinical condition related to hyposideremia in which patients, "when being a bed they betake themselves to sleep" and experienced "in the arms and legs, leapings and contractions of the tendons, and so great a restlessness and tossing of their members ensue, that the diseased are no more able to sleep than if they were in a place of the greatest torture" (Willis, 1672, English quotation taken from Willis, 1685). In these lines Willis firstly reported the main symptomatology of a clinical condition that a century later the German neurologist Theodor Wittmaack named anxietas tibiarum (Wittmaack, 1861) and that currently is referred to as Restless Legs Syndrome (RLS).

The term "Restless Legs Syndrome" was introduced in 1945 by the Swedish neurologist Karl Axel Ekbom. Ekbom used the word "syndrome" because the disorder was defined by clinical symptoms rather than by a specific pathological process (Ekbom, 
1945). Recently, the fundamental contributions of these scholars induced the scientific community to rename RLS as "Willis-Ekbom disease" (WED) (Coccagna et al, 2004; Allen et al, 2014).

RLS/WED is a common neurological disorder characterized by uncomfortable and unpleasant sensations in the legs, with an urge to move. Commonly the patients say that they are "restless," "uncomfortable," "twitchy," that their legs "need to stretch," "urge to move," and "want to move on their own". About half of the patients report their RLS/WED sensations as painful. The symptoms typically begin or worsen during periods of rest or inactivity such as lying down or sitting, while the activity may typically relieve the urge to move and the unpleasant legs sensations. Another important characteristic of RLS/ WED is the worsening of symptoms in the evening or during the night (Allen et al., 2014).

The majority of RLS/WED patients complains of poor sleep (Hening et al., 2004): most patients report some kind of difficulty falling asleep, whereas other patients fall asleep rapidly and wake-up shortly after with unpleasant legs sensations that force them to get up and walk around (Ohayon et al., 2012).

Allen et al. (2005) reported the prevalence of RLS/ WED about 2-3\% in the general population, but recent studies indicated higher frequencies, ranging from 5 to $10 \%$ (Garcia-Borreguero et al., 2006; Garcia-Borreguero and Williams, 2014). However, a number of methodological issues might question these results (Allen et al., 2014). RLS/WED is deemed as a clinically significant condition when its symptoms have a negative impact on sleep, quality of life and health (Winkelman et al., 2009; Fulda et al., 2011; Galbiati et al., 2015).

RLS/WED can be divided into primary and secondary forms. Primary, or idiopathic, RLS/WED refers to patients without associated conditions that may explain the symptoms. Secondary causes of RLS/ WED include pregnancy and iron deficiency. RLS/ WED, in fact, occurs more commonly in subjects with these conditions; however, only approximately one third to one half of patients with these conditions develop RLS/WED.

RLS/WED typically manifests itself as a chronic condition. Little is known about the pattern of expression of mild or intermittent RLS/WED because most patients with this subtype do not seek treatment. It is also unknown whether this group experiences periods of remission. For those with more severe disease who seek medical attention, the severity and frequency of exacerbations usually increase over time. The clinical course varies according to the age of onset. Patients with late-onset RLS/WED generally have a more rapid development of symptoms. On the contrary, patients with early-onset RLS/ WED usually develop symptoms more insidiously over many years, and may not become persistent until age of 40-60 years. Although secondary RLS/ WED appears to remit with correction of the secondary condition, long-term studies are lacking (Allen et al., 2003).

In most of the cases, RLS/WED patients are not aware of Periodic Limb Movements (PLM), but occasionally they can refer of sudden involuntary movements or shacking of the limbs. PLM usually involve the legs and occur at night, especially in the transition from relaxed wakefulness to sleep. When PLM occur during sleep, bed-partner observations may help in the clinical suspect. Subjects with PLM may report some generic associated symptoms such as non refreshing sleep, insomnia or excessive daytime sleepiness. However, the medical history is usually insufficient in sensitivity or specificity to replace instrumental investigations in the diagnosis of PLM. The presence of PLM, positive familial history of RLS/WED and a prompt response of symptoms to dopaminergic therapy are used as supportive data for diagnosis (Manconi et al., 2007).

Over the years a great load of accumulating research and clinical data have led to an extended consensus for a need to enhance the diagnostic criteria. Accordingly, the International Restless Legs Syndrome Study Group (IRLSSG) in 2012 revised the previous 2003 National Institute of Health (NIH)/IRLSSG criteria for RLS/WED in order to improve specificity without changing the fundamental features of the diagnosis. It is important to note that these are the only diagnostic criteria developed by a consensus process involving a large international body of RLS/WED clinical and research experts (Allen et al., 2014).

The aim of this paper is to provide a critical comparison among different diagnostic criteria of RLS/WED, taking into account respectively the International Classification of Sleep Disorders (ICSD), the IRLSSG and the Diagnostic and Statistical Manual of Mental Disorders (DSM). We 
will first overview the historical evolution of each of the diagnostic systems, and then we will compare them taking into account similarities and differences. To facilitate a synoptic account of the diagnostic criteria, we will employ comparative tables for each of the different nosological approaches.

\section{International Classification of Sleep Disorders (ICSD)}

The first version of ICSD was published in 1990 by the American Sleep Disorders Association (ASDA, 1990) as a revision of the Diagnostic Classification of Sleep and Arousal Disorders by the Association of Sleep Disorder Centers (1979). It provided the first official diagnostic criteria for RLS/WED. As for Diagnostic Classification of the Sleep and Arousal Disorders (DCSAD), this classification was made without employing a broad consensus of RLS/WED experts or a review of existing literature.

RLS/WED was classified as an "Intrinsic Sleep Disorder" under the group of "dyssomnias", and described as associated with "disagreeable leg sensations", usually prior to sleep onset, "that cause an almost irresistible urge to move the legs." These features highlighted the symptoms occurring at sleep onset and at night, underestimating patients' symptoms during wakefulness or in the late afternoon and evening.

According to this classification the minimal criteria for the diagnosis were: a) a complaint of an unpleasant sensation in the legs at night or difficulty in initiating sleep; b) disagreeable sensations of "creeping" inside the calves often associated with general aches and pains in the legs; c) the discomfort is relieved by movements of limbs.

Beside these minimal criteria, three others points were added: d) polysomnographic monitoring demonstrating limb movements at sleep onset; e) no evidence of any medical or psychiatric disorders that account for the movements; f) other sleep disorders may be present but do not account for the symptoms. The criterion $d$ was the only one that requested an instrumental examination, although it did not provide a clear quantitative index.

In the 2005 ICSD update by the American Academy of Sleep Medicine (AASM, 2005), RLS/WED has been included in a new category defined "Sleep
Related Movement Disorders". This classification made a distinction between pediatric (age from 2 to 12 years) and adult patients (age older than 12 years). This updated guideline introduced a more specific description of the disorder as shown by criterion $a$ with the "urge to move the legs", and the use of the term paresthesias. In criterion $b$ the feature of the worsening of the symptoms during period of rest or inactivity was introduced. Furthermore another key change is represented by circadian features of RLS/ WED reported in criterion $d$.

In the "associated features" section, significant additions were made: 1) a motor expression of the disorder, impact and definition of PLM during sleep (PLMS) and resting wakefulness (PLMW); 2) the association between depression and anxiety with RLS/WED; 3) the pharmacological response to treatment with levodopa or dopamine-receptor agonists; 4) the involvement of the arms. An important issue raised in ICSD-2 referred to the subjective report of sensory symptoms, underlining the importance of the experiences described by the patients and implying that the only objective measures that support the diagnosis of RLS/WED were PLMS and PLMW, reported in $80-90 \%$ of RLS/WED patients. In 2014 ICSD-3 was released. According to the ICSD-3 (AASM, 2014) five essential criteria are required for the diagnosis of RLS/WED. Criteria al-3 specify the necessary characteristics of the RLS/WED sensations. The separation of worsening at rest (criterion al) from worsening in the evening/night (criterion $a 3$ ), was not present in the previous ICSD-2, and is based on circadian rhythm studies that show an increase of symptoms at night (Trenkwalder et al., 1999).

The most important "mimics" of RLS are leg cramps, positional discomfort, arthralgias/arthritis, myalgias, leg edema, peripheral neuropathy, radiculopathy, and habitual foot tapping. Fulfilling ICSD3 diagnostic criteria $a 2$ (get better with movement) and $a 3$ (worsen in the evening/night) improves specificity for an RLS/WED diagnosis. However, it should be considered that any of RLS/WED mimics can occur also in RLS/WED patients. For example, some patients may suffer from RLS/WED and have leg cramps. When the diagnosis of RLS/WED is not certain, evaluation for the supportive features such as the presence of PLMS or a family history of RLS/ WED may be clearly helpful. 


\begin{tabular}{|c|c|c|}
\hline ICSD-1 Diagnostic criteria for RLS (1990) & ICSD-2 Diagnostic criteria for RLS (2005) & ICSSD-3 Diagnostic criteria for RLS (2014) \\
\hline $\begin{array}{l}\text { a. The patient has a complaint of an } \\
\text { unpleasant sensation in the legs at } \\
\text { night or difficulty in initiating sleep }\end{array}$ & $\begin{array}{l}\text { a. The patient reports an urge to move } \\
\text { the legs, usually accompanied or cau- } \\
\text { sed by uncomfortable and unpleasant } \\
\text { sensations in the legs }\end{array}$ & $\begin{array}{l}\text { a. An urge to move the legs, usually ac- } \\
\text { companied by or felt to be caused by } \\
\text { uncomfortable and unpleasant sensa- } \\
\text { tions in the legs. These symptoms must: } \\
\text { 1. begin or worsen during periods of rest } \\
\text { or inactivity such as lying down or sitting; } \\
\text { 2. be partially or totally relieved by move- } \\
\text { ment, such as walking or stretching, at le- } \\
\text { ast as long as the activity continues; and } \\
\text { 3. they occur exclusively or predomi- } \\
\text { nantly in the evening or night rather } \\
\text { than during the day }\end{array}$ \\
\hline $\begin{array}{l}\text { b. Disagreeable sensations of "cree- } \\
\text { ping" inside the calves often associa- } \\
\text { ted with general aches and pains in } \\
\text { the legs }\end{array}$ & $\begin{array}{l}\text { b. The urge to move or the unpleasant } \\
\text { sensations begin or worsen during pe- } \\
\text { riods of rest or inactivity such as lying } \\
\text { or sitting }\end{array}$ & $\begin{array}{l}\text { b. The above features are not solely ac- } \\
\text { counted for as symptoms of another } \\
\text { medical or a behavioral condition (e.g., } \\
\text { leg cramps, positional discomfort, myal- } \\
\text { gia, venous stasis, leg edema, arthritis, } \\
\text { habitual foot tapping) }\end{array}$ \\
\hline $\begin{array}{l}\text { c. The discomfort is relieved by move- } \\
\text { ments of the limbs }\end{array}$ & $\begin{array}{l}\text { c. The urge to move or unpleasant sen- } \\
\text { sations are partially or totally relieved } \\
\text { by the movements, such as walking or } \\
\text { stretching, at least as long as the acti- } \\
\text { vity continues }\end{array}$ & $\begin{array}{l}\text { c. The symptoms of RLS cause concern, } \\
\text { distress, sleep disturbance, or impai- } \\
\text { rment in mental, physical, social, occu- } \\
\text { pational, educational, behavioral, or } \\
\text { other important areas of functioning }\end{array}$ \\
\hline $\begin{array}{l}\text { d. Polysomnographic monitoring de- } \\
\text { monstrates limb movements at sleep } \\
\text { onset }\end{array}$ & $\begin{array}{l}\text { d. The urge to move or unpleasant sen- } \\
\text { sations are worse, or only occur, in the } \\
\text { evening or night }\end{array}$ & \\
\hline $\begin{array}{l}\text { e. There is no evidence of any medical } \\
\text { or mental disorders that account for the } \\
\text { movements }\end{array}$ & $\begin{array}{l}\text { e. The condition is not better explained } \\
\text { by another current sleep disorder, me- } \\
\text { dical or neurological disorder, mental } \\
\text { disorder, medication use, or substance } \\
\text { use disorder }\end{array}$ & \\
\hline $\begin{array}{l}\text { f. Other sleep disorders may be present } \\
\text { but do not account for the symptom }\end{array}$ & & \\
\hline
\end{tabular}

In agreement with the previous observations, the criterion $b$ states that RLS/WED must be differentiated from other conditions that can mimic the disease. Moreover, the clinical impact of RLS/WED is defined by the symptoms causing substantial distress, sleep disturbance, or impairment of functioning (criterion $c$ ).

Other supportive diagnostic criteria for RLS/WED are similar to ICSD-2. They include: positive family history, presence of PLM, and positive response to dopaminergic drugs. An important point stressed in this update is represented by the quantitative data provided for PLMS (above 5 per hour), observed in almost $80 \%$ of RLS/WED patients.

The differentiation of RLS/WED from other conditions that may have similar characteristics is crucial, since about $40 \%$ of individuals without RLS/WED will report some urge or need to move the legs while at rest (AASM, 2014).

\section{International Restless Legs Syndrome Study Group (IRLSSG)}

In 1995 the 28 founding members of the IRLSSG developed the first diagnostic criteria from a consensus of clinical RLS/WED experts (Walters, 1995). The goal of this group was to improve the observed inadequacy of the former criteria (ASDA, 1990). The core of RLS/WED diagnosis was established by "four minimal criteria": a) desire to move the limbs usually associated with paresthesias/dysesthesias; b) motor restlessness; c) symptoms are worse or exclusively present at rest (i.e., lying, sitting) with at least partial and temporary relief by activity; d) symptoms are worse in evening/night. Moreover, sleep disturbance, involuntary movements, normal neurological examination, clinical course and family history represented additional supportive features of RLS/WED. 
Despite this new set of diagnostic criteria represented a fundamental milestone, the increase of clinical research in the following years shed light on some limitations. They were consequentially updated, redefined in 2002 and published in 2003 by the IRLSSG Foundation in partnership with NIH (Allen et al., 2003).

Three main changes were made. Firstly, the term "motor restlessness" was replaced by "urge to move", which represented the prominent characteristic of the disorder. Secondly, the "relief of symptoms by movement and exacerbation of symptoms by inactivity" became a criterion itself. Third, new diagnostic criteria for children and cognitively impaired elderly were introduced, as well as suggestions on the management of the emergent problem of augmentation.

The consequences of the 2003 NIH/IRLSSG criteria were several. The elucidation of the essential diagnostic criteria supported clinical trials that led to the approval of dopamine agonists for treatment in both Europe and USA (Hening et al., 2004; Aurora et al., 2012; Garcia-Borreguero et al., 2012). For the first time RLS/WED patients had an effective medication readily prescribed both by sleep experts and primary care physicians. Furthermore, the 2003 criteria provided strong basis for the implementation of several studies that account for different aspects of RLS/WED etiopathology (Early et al., 2006; Xiong et al., 2007), and the development of simple questionnaires for large epidemiological surveys (Allen et al., 2005). Anyway, this last aspect revealed also some limitations. Simple three- to four-item tests based on the essential criteria of NIH/IRLSSG raised concerns about their specificity. The risk of the inclusion of false positive RLS/WED in pathophysiological studies could lead to erroneous findings and difficulties in replication of results (Allen et al., 2014). Notably, this version did not provide any specification on the frequency of the symptoms requested for posing a diagnosis. This possibly led to an overestimation of the prevalence of the disease in epidemiological studies and to an overtreatment in daily clinical practice. In 2012, the IRLSSG revised the 2003 NIH/IRLSSG criteria for RLS/WED (Allen et al., 2003; IRLSSG, 2012), which were published in 2014 (www.IRLSSG. org). The 2012 IRLSSG consensus provided a further attempt to improve specificity of diagnosis in clinical and research settings. A fifth criterion has been introduced in order to improve the issues of differential diagnosis, stating that the symptoms are not due to another medical or behavioral condition. This provided an increase in specificity sacrificing some sensitivity in detection of RLS/WED (Moller et al., 2010).

Another important addition was represented by specifiers for clinical course and for clinical significance. When diagnostic criteria are met, specifiers should be applied, if appropriate. They define distinct subgroups of RLS/WED that should be applied both for research purpose and for treatment. Specifiers for clinical course divide the disorder in two 6) cases: a) chronic-persistent RLS/WED (symptoms occurring on average at least twice weekly for the past year if not treated) and b) intermittent RLS/WED (symptoms occurring on average $<2 /$ week for the past year, with at least five lifetime events if not treated). Furthermore, the addition of specifiers for clinical significance underline the dimensional aspects of RLS/ WED in terms of severity that varies across the disorder from mildly annoying to crippling symptoms. This stresses the importance of a careful assessment in order to determine individual treatment decisions. Regarding the supportive features for RLS/WED diagnosis, a difference with respect to $2003 \mathrm{NIH} /$ IRLSSG criteria is represented by the inclusion of the "lack of expected daytime sleepiness". In fact, RLS/WED patients usually have mean Epworth Sleepiness Scale (ESS) scores that are only slightly elevated or within normal range (Saletu et al., 2002). Importantly, this feature alerts the clinician to other possible etiologies whenever excessive sleepiness is present (Allen et al., 2014).

\section{Diagnostic and Statistical Manual of Mental Disorders (DSM)}

In the fourth edition of DSM (1994) the presence of RLS/WED was reported for the first time. However, it was not listed as a diagnostic entity on its own but it was subsumed under the diagnostic category of "Dyssomnia Not Otherwise Specified (NOS)". Only a brief description of the syndrome was given, referring to "uncomfortable sensations" leading to an intense urge to move the legs, beginning in the evening before sleep onset and temporarily relieved by moving the legs or walking. The sensations were described as able to delay sleep onset or awaken the individual from sleep. 
Table II. - IRLSS diagnostic criteria in the 1995, 2003 and 2012 update

\begin{tabular}{|c|c|c|}
\hline IRLSSG, 1995 & NIH/IRLSSG, 2003 & IRLSSG, 2012 \\
\hline $\begin{array}{l}\text { a. Desire to move the limbs usually asso- } \\
\text { ciated with paresthesias/dysesthesias }\end{array}$ & $\begin{array}{l}\text { a. An urge to move the legs, usually } \\
\text { accompanied or caused by uncomfor- } \\
\text { table and unpleasant sensations in } \\
\text { the legs (Sometimes the urge to move } \\
\text { is present without the uncomfortable } \\
\text { sensations and sometimes the arms or } \\
\text { other body parts are involved in addi- } \\
\text { tion to the legs) }\end{array}$ & $\begin{array}{l}\text { a. An urge to move the legs usually but } \\
\text { not always accompanied by, or felt } \\
\text { to be caused by, uncomfortable and } \\
\text { unpleasant sensations in the legs }\end{array}$ \\
\hline b. Motor restlessness & $\begin{array}{l}\text { b. The urge to move or unpleasant sen- } \\
\text { sations begin or worsen during periods } \\
\text { of rest or inactivity such as lying or sit- } \\
\text { ting }\end{array}$ & $\begin{array}{l}\text { b. The urge to move the legs and any } \\
\text { accompanying unpleasant sensations } \\
\text { begin or worsen during periods of rest } \\
\text { or inactivity such as lying down or sitting }\end{array}$ \\
\hline $\begin{array}{l}\text { c. Symptoms are worse or exclusively pre- } \\
\text { sent at rest (i.e., lying, sitting) with at least } \\
\text { partial and temporary relief by activity }\end{array}$ & $\begin{array}{l}\text { c. The urge to move or unpleasant } \\
\text { sensations are partially or totally relie- } \\
\text { ved by movement, such as walking or } \\
\text { stretching, at least as long as the acti- } \\
\text { vity continues }\end{array}$ & $\begin{array}{l}\text { c. The urge to move the legs and any } \\
\text { accompanying unpleasant sensations } \\
\text { are partially or totally relieved by move- } \\
\text { ment, such as walking or stretching, at } \\
\text { least as long as the activity continues }\end{array}$ \\
\hline $\begin{array}{l}\text { d. Symptoms are worse in evening/ } \\
\text { night }\end{array}$ & $\begin{array}{l}\text { d. The urge to move or unpleasant } \\
\text { sensations are worse in the evening or } \\
\text { night than during the day or only oc- } \\
\text { cur in the evening or night (When sym- } \\
\text { ptoms are very severe, the worsening at } \\
\text { night may not be noticeable but must } \\
\text { have been previously present) }\end{array}$ & $\begin{array}{l}\text { d. The urge to move the legs and any } \\
\text { accompanying unpleasant sensations } \\
\text { during rest or inactivity only occur or } \\
\text { are worse in the evening or night than } \\
\text { during the day }\end{array}$ \\
\hline & & $\begin{array}{l}\text { e. The occurrence of the above features } \\
\text { is not solely accounted for as symptoms } \\
\text { primary to another medical or a behavio- } \\
\text { ral condition (e.g. myalgia, venous stasis, } \\
\text { leg edema, arthritis, leg cramps, positio- } \\
\text { nal discomfort, habitual foot tapping) }\end{array}$ \\
\hline
\end{tabular}

Six years later, the DSM IV-Text Revised (TR) (2000) still did not provide a specific diagnostic category for RLS/WED which was again posed under the group of "Dyssomnia NOS". However, this time a more specific description of the symptomatology was given. First of all, objective features were reported, like the presence of PLMS, evidence of anemia or reduced serum iron as well as a normal electrophysiological and brain morphology. Moreover, a distinction between idiopathic RLS/WED and RLS/WED associated with general medical or neurological conditions (including pregnancy) was furnished. Finally, a brief epidemiological and clinical characterization was offered.

With the release of the fifth edition of DSM, RLS/ WED became a separate diagnostic entity. This was due to the necessity of defining a clinically significant condition that was commonly encountered in daily psychiatric practice (American Psychiatric Association, 2013).

Five diagnostic criteria were identified and a requirement for frequency (at least three times per week) and duration (at least 3 months) was included. This was an addition to DSM IV-TR that trivialized the potential clinical significance of the intermittent subtypes or recent/onset RLS/WED. Furthermore in the "diagnostic marker" section, polysomnographic findings like an increase latency to sleep and higher arousal index have been introduced. In addition, comorbidities with depressive, anxiety, and attentional disorders, as well as cardiovascular and metabolic disorders were reported. Particular attention was given to distress or impairment in social, occupational, educational, academic, behavioral, or other important areas of functioning (criterion $c$ ).

\section{Comparison between ICSD-3, IRLLSG 2012 e DSM V}

There are several remarkable distinctions between the IRLSSG revised criteria, ICSD-3 and DSM-V. One of the most striking difference is the requirement of frequency of RLS/WED in DSM-V, which 
Table III. - RLS/WED diagnostic criteria in DSM-IV, DSM IV-TR and DSM V

\begin{tabular}{|c|c|c|}
\hline $\begin{array}{c}\text { Diagnostic and Statistical Manual of } \\
\text { Mental Disorders } \\
\text { IV (1994) }\end{array}$ & $\begin{array}{c}\text { Diagnostic and Statistical Manual of } \\
\text { Mental Disorders } \\
\text { IV-TR (2000) }\end{array}$ & $\begin{array}{l}\text { Diagnostic and Statistical Manual of } \\
\text { Mental Disorders } \\
\text { V (2013) }\end{array}$ \\
\hline $\begin{array}{l}\text { Idiopathic "Restless Legs Syndrome": } \\
\text { uncomfortable sensations (e.g., dis- } \\
\text { comfort, crawling sensations, or restless- } \\
\text { ness) that lead to an intense urge to } \\
\text { move the legs. Typically, the sensations } \\
\text { begin in the evening before sleep onset } \\
\text { and are temporarily relieved by moving } \\
\text { the legs or walking, only to begin again } \\
\text { when the legs are immobile. The sensa- } \\
\text { tions can delay sleep onset or awaken } \\
\text { the individual from sleep }\end{array}$ & 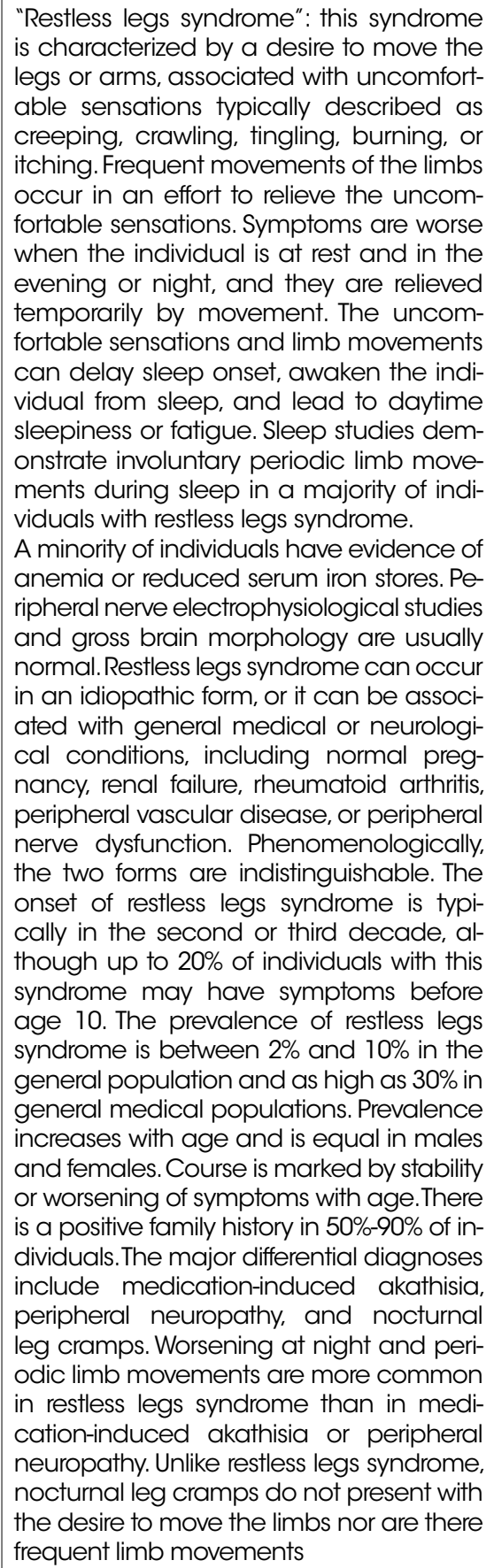 & $\begin{array}{l}\text { a. An urge to move the legs, usually } \\
\text { accompanied by or in response to } \\
\text { uncomfortable and unpleasant sensa- } \\
\text { tions in the legs, characterized by all of } \\
\text { the following: } \\
\text { 1. The urge to move the legs begins or } \\
\text { worsens during periods of rest or inac- } \\
\text { tivity } \\
\text { 2. The urge to move the legs is partially } \\
\text { or totally relieved by movement } \\
\text { 3. The urge to move the legs is worse in } \\
\text { the evening or at night than during the } \\
\text { day, or occurs only in the evening or at } \\
\text { night } \\
\text { b. The symptoms in Criterion A occur at } \\
\text { least three times per week and have } \\
\text { persisted for at least } 3 \text { months } \\
\text { c. The symptoms in Criterion A are ac- } \\
\text { companied by significant distress or } \\
\text { impairment in social, occupational, } \\
\text { educational, academic, behavioral, or } \\
\text { other important areas of functioning } \\
\text { d. The symptoms in Criterion A are not } \\
\text { attributable to another mental disor- } \\
\text { der or medical condition (e.g., arthritis, } \\
\text { leg edema, peripheral ischemia, leg } \\
\text { cramps) and are not better explained } \\
\text { by a behavioral condition (e.g., po- } \\
\text { sitional discomfort, habitual foot tap- } \\
\text { ping) } \\
\text { e. The symptoms are not attributable to } \\
\text { the physiological effects of a drug of } \\
\text { abuse or medication (e.g., akathisia) }\end{array}$ \\
\hline
\end{tabular}

is not present in the IRLSSG revised criteria. This point, while setting an improved diagnostic specificity, can undervalue the importance of the clinical course of the disease, which characterizes RLS/WED more effectively. A possible risk of this approach is therefore to underestimate the clinical significance of the "intermittent" or "recentonset" RLS/WED subtype. IRLSSG deems clinical course as an important distinction among RLS/WED patients. Some patients have a sporadic and infre- 
quent occurrence of symptoms while others have a more constant symptomatology. Generally, there is a strong agreement among RLS/WED experts on the importance to investigate the disorder independently of its frequency (Allen et al., 2014).

Furthermore, DSM-V defines a confined clinical spectrum of RLS/WED by demanding the symptoms to be "accompanied by significant distress or impairment in social, occupational, education, academic, behavioral or other important areas of functioning". On the contrary, IRLSSG revised criteria define a full spectrum of RLS/WED. The DSM-V approach to this topic seems to confound the intrinsic severity of the disorder with lifestyle impact of the symptoms.

Compared to the DSM-V, ICSD-3 diagnostic criteria are more aligned to the IRLSSG ones. In fact, the five essential criteria of the IRLSSG are also required for the diagnosis of RLS/WED according to ICSD-3. Moreover, the lack of frequency and duration specifications, that are instead two important features of the DSM-V criteria, represents another notable similarity between the ICSD-3 and IRLSSG revised criteria.

Another diagnostic feature that is not reported in DSM-V and ICSD-3 is the variable course of RLS/ WED. In the IRLSSG revised criteria specifiers for clinical course and for clinical significance provide a dimensionality of RLS/WED, from mild, infrequent episodes to severe, chronic-persistent RLS/WED. This offers the clinicians the flexibility to individualize treatment decision for RLS/WED patients (Garcia-Borreguero et al., 2011; Silber et al., 2013). Furthermore, the avoidance of a dichotomous categorization based only on the frequency of symptoms is helpful in keeping away from misclassifying intermittent and severe RLS/WED or mild and persistent RLS/WED.

Moreover, the new IRLSSG fifth criterion focused the attention on differential diagnosis, encouraging the development of standardized and validated methods aimed at improving case clarification. This point is of particular importance on large questionnaire-based surveys.

Taken together, the new IRLSSG criteria provide a more rigorous approach to case ascertainment and a better characterization of patients by specifying clinical significance and course. Despite DSM-V has distinguished RLS/WED as a separate diagnostic entity, the scientific progresses made by RLS/WED researchers have not been completely introduced in the manual. While ICSD-3 adequately integrates the IRLSSG revised criteria, DSM-V handles RLS/ WED in a slightly different manner, posing particular attention on the frequency of symptoms.

In agreement with the DSM-V nosology, both ICSD3 and IRLSSG revised criteria take into account the clinical significance of the overall patients' functioning. However, an important difference between the two latter approaches is that ICSD-3 includes this issue among the diagnostic criteria whereas IRLSSG handles it just as clinical specifiers.

The IRLSSG revised diagnostic criteria aim to contribute to the field by improving diagnostic validity and case ascertainment and by facilitating clear communication among RLS/WED clinicians and researchers. The current revision of diagnostic criteria was undertaken with respect and appreciation for the earlier work by the pioneers in the field of RLS/ WED and aims to avoid arbitrary alteration of current clinical practice and research without available supporting empirical evidence.

Future ascertainment of correct diagnosis in a clinical or research setting should include documentation that all five diagnostic criteria are considered. Efforts in developing diagnostic and case ascertainment instruments should be accompanied by research for objective and reliable biomarkers for RLS/WED. The ongoing advances in research on the pathophysiology of RLS/WED indicate possible underlying biological and genetic features that alone or combined with clinical symptoms may provide the basis for the next advance in the RLS/WED diagnostic criteria.

\section{References}

Allen R.P., Picchietti D., Hening W.A., Trenkwalder C., Walters A.S., Montplaisir J.; Restless legs Syndrome Diagnosis and Epidemiology workshop at the National Institutes of Health; International Restless Legs Syndrome Study Group. Restless legs syndrome: diagnostic criteria, special considerations, and epidemiology. A report from the restless legs syndrome diagnosis and epidemiology workshop at the National Institutes of Health. Sleep Med., 4: 101-119, 2003.

Allen R.P., Walters A.S., Montplaisir J., Hening W., Myers A., Bell T.J., Ferini-Strambi L. Restless 
legs syndrome prevalence and impact: REST general population study. Archs. Intern. Med., 165: 1286-1292, 2005.

Allen R.P., Picchietti D.L., Garcia-Borreguero D., Ondo W.G., Walters A.S., Winkelman J.W., Zucconi M., Ferri R., Trenkwalder C., Lee H.B.; International Restless Legs Syndrome Study Group. Restless legs syndrome/Willis-Ekbom disease diagnostic criteria: updated International Restless Legs Syndrome Study Group (IRLSSG) consensus criteria-history, rationale, description, and significance. Sleep Med., 15: 860-873, 2014.

American Academy of Sleep Medicine. The international classification of sleep disorders: diagnostic and coding manual, 2nd ed. Westchester, IL: American Academy of Sleep Medicine, 2005.

American Academy of Sleep Medicine. The international classification of sleep disorders, 3rd ed. Darien, IL: American Academy of Sleep Medicine, 2014.

American Psychiatric Association. Diagnostic and statistical manual of mental disorders, 4th ed. Washington, DC: The American Psychiatric Association, 1994.

American Psychiatric Association. Diagnostic and statistical manual of mental disorders, 4th ed., text revision. American Psychiatric Association, Washington, DC, 2000.

American Psychiatric Association. Diagnostic and statistical manual of mental disorders, 5th ed. APA, Arlington (VA), 2013.

American Sleep Disorders Association. The international classification of sleep disorders: diagnostic and coding manual. Rochester, MN: ASDA, 1990.

Association of Sleep Disorders Centers. Diagnostic classification of sleep and arousal disorders. Sleep, 2: 1-154, 1979.

Aurora R.N., Kristo D.A., Bista S.R., Rowley J.A., Zak R.S., Casey K.R., Lamm C.I., Tracy S.L., Rosenberg R.S.; American Academy of Sleep Medicine. The treatment of restless legs syndrome and periodic limb movement disorder in adults - an update for 2012: practice parameters with an evidence-based systematic review and metaanalyses. Sleep, 35: 1039-1062, 2012.

Coccagna G., Vetrugno R., Lombardi C., Provini F. Restless legs syndrome: an historical note. Sleep Med., 5: 279-283, 2004.

Earley C.J., Barker P.B., Horska A., Allen R.P. MRIdetermined regional brain iron concentrations in early- and late-onset restless legs syndrome. Sleep Med., 7: 458-461, 2006.
Ekbom K.A. Restless legs syndrome. Acta Med. Scand., 158(Suppl.): 1-123, 1945.

Fulda S., Szesny N., Ising M., Heck A., Grübl A., Lieb R., Reppermund S. Further evidence for executive dysfunction in subjects with RLS from a nonclinical sample. Sleep Med., 12: 1003-1007, 2011.

Galbiati A., Marelli S., Giora E., Zucconi M., Oldani A., Ferini-Strambi L. Neurocognitive function in patients with idiopathic Restless Legs Syndrome before and after treatment with dopamine-agonist. Int. J. Psychophysiol., 95: 304-309, 2015.

Garcia-Borreguero D., Egatz R., Winkelmann J., Berger K. Epidemiology of restless legs syndrome: the current status. Sleep Med. Rev., 10: 153-167, 2006.

Garcia-Borreguero D., Stillman P., Benes H., Buschmann H., Chaudhuri K.R., Gonzalez Rodríguez V.M., Högl B., Kohnen R., Monti G.C., Stiasny-Kolster K., Trenkwalder C., Williams A.M., Zucconi M. Algorithms for the diagnosis and treatment of restless legs syndrome in primary care. BMC Neurol., 11: 28, 2011.

Garcia-Borreguero D., Ferini-Strambi L., Kohnen R., O'Keeffe S., Trenkwalder C., Högl B., Benes H., Jennum P., Partinen M., Fer D., Montagna P., Bassetti C.L., Iranzo A., Sonka K., Williams A.M.; European Federation of Neurological Societies; European Neurological Society; European Sleep Research Society. European guidelines on management of restless legs syndrome: report of a joint task force by the European Federation of Neurological Societies, the European Neurological Society and the European Sleep Research Society. Eur. J. Neurol., 19: 1385-1396, 2012.

Garcia-Borreguero D., Williams A.M. An update on restless legs syndrome (Willis-Ekbom disease): clinical features, pathogenesis and treatment. Curr. Opin. Neurol., 27: 493-501, 2014.

Hening W., Walters A., Allen R.P., Montplaisir J., Myers A., Ferini-Strambi L. Impact, diagnosis and treatment of restless legs syndrome (RLS) in a primary care population: the REST (RLS epidemiology, symptoms and treatment) primary care study. Sleep Med., 5: 237-246, 2004.

International Restless Legs Study Group. IRLSSG diagnostic criteria for RLS, 2012. Available at: www.irlssg.org.

Manconi M., Ferri R., Zucconi M., Oldani A., Fantini M.L., Castronovo V., Ferini-Strambi L. First night efficacy of pramipexole in restless legs syndrome and periodic leg movements. Sleep Med., 8: 491497, 2007. 
Moller C., Wetter T.C., Koster J., Stiasny-Kolster K. Differential diagnosis of unpleasant sensations in the legs: prevalence of restless legs syndrome in a primary care population. Sleep Med., 11: 161-166, 2010.

Ohayon M.M., O'Hara R., Vitiello M.V.Epidemiology of restless legs syndrome: a synthesis of the literature. Sleep Med. Rev. 16: 283-295, 2012.

Saletu B., Anderer P., Saletu M., Hauer C., LindeckPozza L., Saletu-Zyhlarz G. EEG mapping, psychometric, and polysomnographic studies in restless legs syndrome (RLS) and periodic limb movement disorder (PLMD) patients as compared with normal controls. Sleep Med., 3(Suppl.): S3542, 2002.

Silber M.H., Becker P.M., Earley C., GarciaBorreguero D., Ondo W.G.; Medical Advisory Board of the Willis-Ekbom Disease Foundation. Willis-Ekbom Disease Foundation revised consensus statement on the management of restless legs syndrome. Mayo Clin. Proc., 88: 977-986, 2013.

Trenkwalder C., Hening W.A., Walters A.S., Campbell S.S., Rahman K., Chokroverty S.
Circadian rhythm of periodic limb movements and sensory symptoms of restless legs syndrome. Mov. Disord., 14: 102-110, 1999.

Walters A.S., Toward a better definition of the restless legs syndrome. The International Restless Legs Study Group. Mov. Disord., 10: 634-642, 1995.

Willis T. De anima brutorum. London, 1672.

Willis T. The London practice of physick. London, Basset T. and Cooke W., 1685.

Winkelman J.W., Redline S., Baldwin C.M., Resnick H.E., Newman A.B., Gottlieb D.J. Polysomnographic and health-related quality of life correlates of restless legs syndrome in the Sleep Heart Health Study. Sleep, 32: 772-778, 2009.

Wittmaack T., Pathologie und Therapie der Sensibilität-Neurosen. Lipsia, Schäfer, 1861.

Xiong L., Jang K., Montplaisir J., Levchenko A., Thibodeau P., Gaspar C., Turecki G., Rouleau G.A. Canadian restless legs syndrome twin study. Neurology, 68: 1631-1633, 2007. 